\title{
Screening for latent tuberculosis infection among undocumented immigrants in Swiss healthcare centres; a descriptive exploratory study
}

\author{
Patrick Bodenmann*1, Paul Vaucher ${ }^{1}$, Hans Wolff' ${ }^{2}$, Bernard Favrat ${ }^{1}$, \\ Fanny de Tribolet ${ }^{3}$, Eric Masserey ${ }^{4}$ and Jean-Pierre Zellweger ${ }^{1}$
}

Address: ${ }^{1}$ Department of Ambulatory Care and Community Medicine, University of Lausanne, Switzerland, ${ }^{2}$ Department of Community Medicine, Geneva University Hospital, Switzerland, ${ }^{3}$ Point d'Eau, Vulnerable Population Urban Healthcare Centre, Lausanne, Switzerland and ${ }^{4}$ Department of Public Health, Canton of Vaud, Switzerland

Email: Patrick Bodenmann* - patrick.bodenmann@hospvd.ch; Paul Vaucher - paul.vaucher@hospvd.ch; Hans Wolff - hans.wolff@hcuge.ch; Bernard Favrat - bernard.favrat@hospvd.ch; Fanny de Tribolet - pointdeau@bluewin.ch; Eric Masserey - eric.masserey@vd.ch; Jean-

Pierre Zellweger - zellwegerjp@swissonline.ch

* Corresponding author

Published: 24 March 2009

BMC Infectious Diseases 2009, 9:34 doi:10.1186/147/-2334-9-34

This article is available from: http://www.biomedcentral.com/I47I-2334/9/34

(C) 2009 Bodenmann et al; licensee BioMed Central Ltd.

This is an Open Access article distributed under the terms of the Creative Commons Attribution License (http://creativecommons.org/licenses/by/2.0), which permits unrestricted use, distribution, and reproduction in any medium, provided the original work is properly cited.
Received: 23 September 2008

Accepted: 24 March 2009

\begin{abstract}
Background: Migration is one of the major causes of tuberculosis in developed countries. Undocumented patients are usually not screened at the border and are not covered by a health insurance increasing their risk of developing the disease unnoticed. Urban health centres could help identify this population at risk. The objective of this study is to assess the prevalence of latent tuberculosis infection (LTBI) and adherence to preventive treatment in a population of undocumented immigrant patients.
\end{abstract}

Methods: All consecutive undocumented patients that visited two urban healthcare centres for vulnerable populations in Lausanne, Switzerland for the first time were offered tuberculosis screening with an interferon- $\gamma$ assay. Preventive treatment was offered if indicated. Adherence to treatment was evaluated monthly over a nine month period.

Results: Of the 161 participants, 131 (81.4\%) agreed to screening and 125 had complete examinations. Twenty-four of the 125 patients (19.2\%; Cl95\% 12.7;27.2) had positive interferon- $\gamma$ assay results, two of which had active tuberculosis. Only five patients with LTBI completed full preventive treatments. Five others initiated the treatment but did not follow through.

Conclusion: Screening for tuberculosis infection in this hard-to-reach population is feasible in dedicated urban clinics, and the prevalence of LTBI is high in this vulnerable population. However, the low adherence to treatment is an important public health concern, and new strategies are needed to address this problem.

\section{Background}

Each year, more than 8 million people develop active tuberculosis (TB) worldwide with regional variability. It is the most common cause of death from communicable diseases $[1,2]$. Movement of people between countries has a large influence on the incidence of $\mathrm{TB}$ in Western- 
Europe [3-5]. Several studies have shown that most reported cases are due to reactivation of infections acquired abroad but that transmission to other people in the host country is rare [6-9]. Therefore, screening for tuberculosis among immigrants is performed in many developed countries with the aim of detecting and treating the active disease $[10,11]$ or a latent tuberculosis infection (LTBI) [12-14]. The introduction of interferon- $\gamma$ assays has improved specificity for detecting LTBI compared with the tuberculin skin test $[15,16]$. This promises a considerable improvement in the cost-effectiveness of targeted screening programs [17-20]. However, there is no clear consensus regarding the true benefits of screening and it is difficult to assess treatment policies [21].

In practice, screening policies address immigrants that enter into the country via an official channel (asylum claim \& working permit). In Switzerland, a screening policy exists for asylum seekers and refugees at the border, but no system exists for undocumented immigrants from countries with a high prevalence of tuberculosis [22,23]. The latter represent a large proportion of the foreign-born population (estimates vary between 150,000 and 300,000 people for a total immigrant population of 7.5 million) [24]. Targeted screening programs may be cost-effective [25], but further studies are needed to evaluate the prevalence of LTBI, the acceptability of screening, and adherence to treatment in this hard-to-reach vulnerable population.

\section{Methods}

We conducted a pilot trial to investigate the acceptance, prevalence of positive findings, and adherence to treatment of undocumented immigrant patients offered LTBI screening. We offered a free tuberculosis screening procedure to all consecutive, undocumented immigrants that were over 15 years old, had no major psychiatric disabilities, and were visiting one of two low-threshold healthcare premises for the first time in Lausanne. The recruitment proceeded during a six-month period in 2007 at the Department of Ambulatory Care and Community Medicine of the University Hospital and at the Point d'Eau, Vulnerable population urban healthcare centre. Patients were evaluated by nurse practitioners or primary care physicians trained in community medicine.

Patients were asked to answer a health questionnaire in their preferred language that highlighted symptoms or history that might be associated with tuberculosis (cough, sputum, night sweating, weight loss, prior contact with tuberculosis, prior treatment for tuberculosis, and smoking). From each patient, $8 \mathrm{ml}$ of blood was collected in a Vacutainer-CPT. Within the next $24 \mathrm{~h}$, an enzyme-linked immunospot $\gamma$-interferon assay (T-Spot.TB ${ }^{\mathrm{TM}}$, Oxford
Immunotec) was performed to assess the previous tuberculosis infection status. This test has been shown to have a sensitivity of $90 \%$ and a specificity of $93 \%$ to detect latent tuberculosis [26]. If results were inconclusive, the assay was repeated. Patients with suspect symptoms, a prior history of tuberculosis, prior contact with tuberculosis, or a positive interferon- $\gamma$ test result had a chest X-ray and a medical examination by a physician. A bacteriological examination of sputum was performed in all patients that had suspected symptoms or an abnormal X-ray. Patients with active tuberculosis were treated in our Department according to the current Swiss Guidelines $[27,28]$. Patients that had a positive interferon- $\gamma$ assay with no signs of tuberculosis were offered preventive treatment. Treated patients were followed for a six-month period. We monitored the acceptance of screening, the number of patients that returned for test results, the number of patients that accepted treatment, and the number of patients that finished treatment.

Sample size was calculated to assure a 0.1 margin of error for the LTBI prevalence rate with a significant level set at $95 \%$ and an expected prevalence of 0.5 (worse case scenario). We estimated that 97 patients were necessary to sufficiently power the analysis. In anticipation of loss to follow-up and missing data, we included 130 participants in the study. Prevalence and acceptance rates are given with a 95\% confidence interval. Other results are given in a descriptive form without inference, as we expected small sample sizes.

All patients provided written informed consent for participation, the protocol was approved by the Lausanne University Ethical Committee (protocol 183/06), and the study conformed to the standards defined in the Declaration of Helsinki.

\section{Results}

Between January and July 2007, 161 undocumented immigrants that visited one of two medical centres for the first time were asked to participate in this study. Among these, 131 agreed to answer a questionnaire regarding symptoms and history associated with tuberculosis and had a blood sample drawn for an interferon- $\gamma$ assay. The questionnaire acceptance rate was $81.4 \%$ (CI95\% $74.5 ; 87.1)$. However, of these 131 patients, two patients left the waiting room before seeing the practitioner, and one refused to give a blood sample. Thus, 128 laboratory samples were tested, and five of these were inconclusive. Twenty-five patients (19.5\%) did not return for their test results, and three of these had an initial inconclusive laboratory result. Confirmation of the inconclusive essay revealed on positive and one negative patient. Laboratory results were therefore available for 125 patients (Figure 1). 


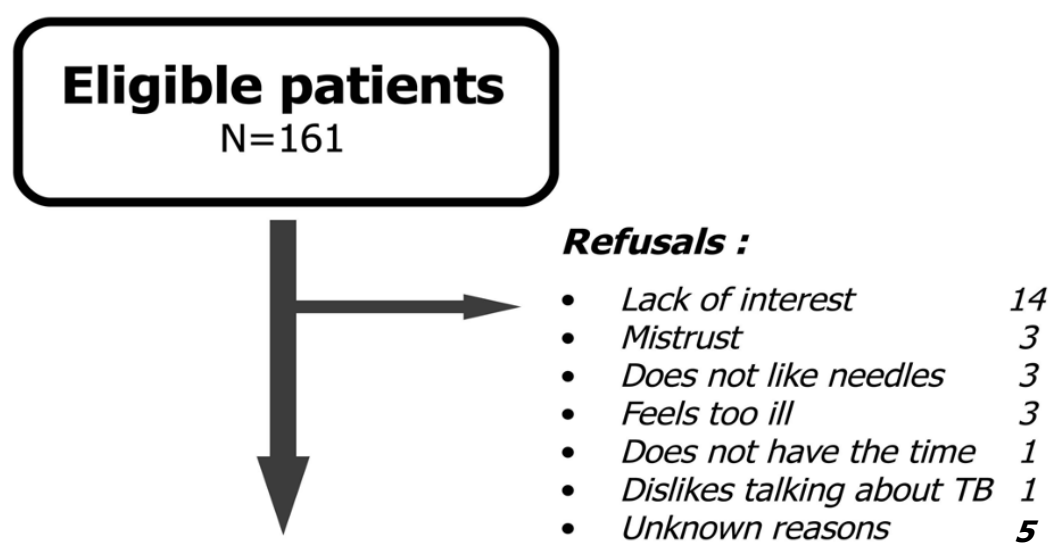

\section{Patients included} $n=131(81.4 \%)$

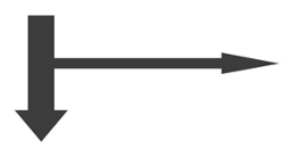

Drop-outs :

- Left before having seen practitioner

2

$$
\begin{gathered}
14 \\
3 \\
3 \\
3 \\
1 \\
1 \\
5
\end{gathered}
$$$$
3
$$$$
3
$$ 
The demographic data are given in Table 1 . The mean age of the participants was 34.8 years, $47.2 \%$ were female, and $64 \%$ were single. Most of the patients (83.2\%) entered Switzerland without receiving the official tuberculosis screening procedure for asylum seekers. The majority of patients were undocumented immigrants born in Latin America (51.2\%), and many were from Sub-Saharan Africa (19.2\%). Most of the patients (76.8\%) were from countries that had a high incidence rate of active tuberculosis ( $\geq 50 / 100,000$ per year). The mean length of time spent in Switzerland was under two years for $52.8 \%$ of the population. Only five out of the 24 participants that tested positive and 15 of the 101 participants that tested negative for TB reported previous contact with a person that had TB Thus, the sensitivity of this question was $20.8 \%$ and the specificity was $85.1 \%$.

The interferon- $\gamma$ assay indicated that 24 immigrants were positive for TB (19.2\%) [CI 95\% 12.7-27.2]. Of these, two had smear-positive tuberculosis (1.6\%) [CI95\% 0.25.7], three had a history of prior treatment for tuberculosis, one had a history of prior treatment for LTBI, and 18 had no active or prior tuberculosis (14.4\%, CI95\% $8.8-$ 21.8 ). One patient was suspected to falsely have a negative

Table I: Population characteristics

\begin{tabular}{|c|c|c|c|}
\hline \multirow[t]{2}{*}{ Population characteristic } & \multicolumn{2}{|c|}{ Interferon $-\gamma$ assay } & \multirow{2}{*}{$\begin{array}{c}\text { Total } \\
n=125 \\
n(\%)\end{array}$} \\
\hline & $\begin{array}{c}\text { Positive } \\
\mathrm{n}=24 \\
\mathrm{n}(\%)\end{array}$ & $\begin{array}{c}\text { Negative } \\
\mathrm{n}=10 \mathrm{I} \\
\mathrm{n}(\%)\end{array}$ & \\
\hline \multicolumn{4}{|l|}{ Age } \\
\hline$<20$ & $0(0)$ & $3(3.0)$ & $3(2.4)$ \\
\hline $20-39$ & $13(54)$ & $78(77)$ & $91(72.8)$ \\
\hline $40-59$ & $11(46)$ & $18(18))$ & $29(23.2)$ \\
\hline 60 or more & $0(0)$ & $2(2)$ & $2(1.6)$ \\
\hline \multicolumn{4}{|l|}{ Gender } \\
\hline Male & $13(54)$ & $53(52)$ & $66(52.8)$ \\
\hline \multicolumn{4}{|l|}{ Level of education } \\
\hline Compulsory or less & II (46) & $46(46)$ & $55(45.6)$ \\
\hline \multicolumn{4}{|l|}{ Reasons for migrating } \\
\hline Economical & $16(64)$ & $63(63)$ & 79 (63.2) \\
\hline Political persecution & $2(8)$ & $19(19)$ & $21(16.8)$ \\
\hline Religious persecution & I (4) & $2(2)$ & $3(2.4)$ \\
\hline Disease & $4(I 7)$ & $2(2)$ & $6(4.8)$ \\
\hline Family grouping & $4(17)$ & $16(16)$ & $20(16)$ \\
\hline Studies & $2(8)$ & $8(8)$ & $10(8.0)$ \\
\hline Other & I (4) & $6(6)$ & $7(5.6)$ \\
\hline \multicolumn{4}{|l|}{ Arrived in Switzerland } \\
\hline Less than 2 years & $12(48)$ & $54(54)$ & $66(52.8)$ \\
\hline $2-7$ years & $6(25)$ & $38(38)$ & 44 (35.2) \\
\hline More than 7 years & $6(24)$ & $9(9)$ & $15(12.0)$ \\
\hline \multicolumn{4}{|l|}{ Tobacco } \\
\hline Smoker & $9(37)$ & $39(39)$ & $48(38.4)$ \\
\hline \multicolumn{4}{|l|}{ Close contact with TBC } \\
\hline Reported & $5(2 I)$ & $15(15)$ & $20(16.0)$ \\
\hline Not reported & $19(79)$ & $86(85)$ & $20(84.0)$ \\
\hline \multicolumn{4}{|c|}{ Proximity of at least one hour with someone during previous 3 months } \\
\hline Disco or dancing & $8(33)$ & $43(43)$ & $51(40.8)$ \\
\hline Religious meetings & $10(42)$ & $4 I(4 I)$ & $51(40.8)$ \\
\hline Interior sports & I (4) & $22(22)$ & $23(18.4)$ \\
\hline Restaurants or pubs & $4(I 7)$ & $16(16)$ & $20(16)$ \\
\hline Welfare hostel & I (4) & $5(4)$ & $6(4.8)$ \\
\hline Other & I (4) & $8(8)$ & $9(7.2)$ \\
\hline
\end{tabular}


interferon- $\gamma$ assays as he had been treated for a sputum confirmed active tuberculosis two years previously.

The two patients with active tuberculosis were isolated and treated according to the current Swiss Guidelines [27]. Both were adherent to treatment and were cured. Among the 14 immigrants with no prior history of TB and a positive interferon- $\gamma$ assay result, four had counter-indications for preventive treatment (high age, liver disease), four did not show up for further examinations, and 10 accepted preventive treatment for LTBI. Of the 10 that accepted preventative treatment, only five followed the treatment until the scheduled completion. Therefore, full treatment was sustained by 5/18 patients with LTBI (Figure 2).

\section{Discussion}

In our study, $19.2 \%(24 / 125)$ of the undocumented immigrant patients had positive interferon- $\gamma$ assay results and $14.4 \%(18 / 125)$ had LTBI that was previously undetected. Carvalho et al [25] found similar results (15\%; 15/ 100) for undocumented immigrant patients attending an Italian health care service. Although the sample sizes were small in both these studies, the observed prevalence of positive interferon- $\gamma$ results appeared to be substantial compared to other population groups, including: German subjects that had been in close contact with an index case $(10 \%)$ [29], healthcare workers in Denmark (1.4\%)[30] or Japan (9.9\%)[31], American Navy recruits (0.6\%)[32], and the general Japanese population (7.1\%)[33]. Prior exposure to an index case with pulmonary TB in the country of origin appeared to be the primary cause of LTBI in low-incidence rate countries [3]. Furthermore, the risk of reactivating a LTBI into active tuberculosis seemed to mainly be related to the initial exposure in high incidence countries of origin and not to other risk behaviours or environmental conditions in the host country $[7,34]$. More than 3/4 of undocumented immigrants consulting healthcare centres in Western Switzerland are from countries with incidence rates of tuberculosis above 50 cases/ 100,000 people per year. This is most likely the major reason for the high prevalence of LTBI in this population.

Targeted tuberculosis screening seems to be more costeffective for preventing outbreaks than systematic screening $[17,21]$. Clinical trials have shown that preventive treatment reduced infection rates by more than half when strict adherence was achieved $[14,35]$. Most cost-effectiveness studies [18-20,36,37] are based on estimates that do not take into consideration the number of positive interferon- $\gamma$ assays that are due to past infections where treatment was interrupted. Nevertheless, our study showed a potential benefit of screening and offering preventive therapy for this specific vulnerable population. Preventing the emergence of new index cases in this hard-to-reach population that often lives in close quarters could substantially reduce expenses related to controlling an outbreak [38]. The high prevalence of LTBI suggests that screening with an interferon- $\gamma$ assay could be cost-effective under conditions that promoted adherence to the end of therapy for most patients [36]. However, the risk of developing tuberculosis is much higher for individuals with positive intereron- $\gamma$ results than those with a positive tuberculosis skin test [39].

The acceptance rate for screening was high (81.4\%). Using nurse practitioners and trained primary physicians in secure environments could help build the trust of this hard-to-reach population. Maintaining confidentiality could be essential to assure trust [40].

On the other hand, there are obstacles in ensuring that patients follow their treatment to the end. Only five patients out of eighteen with LTBI completed the preventive therapy in our study. Ailinger et al [41] observed an adherence prevalence of $72 \%$ for Latino patients that were undocumented immigrants in Washington DC. A prior study from our institution observed that the rate of adherence was $76 \%$ in a group composed mainly of foreign workers and refugees [42]. Therefore, adherence to treatment may depend on the setting and the confidence the patients have in the system (fear of denunciation and rejection). Supervising [43] or monitoring [44] drug administration, offering free access to care [45], using models of explanation based on the patient's representation of his own health [46], and relying on trained nurse practitioners for screening $[47,48]$ could improve compliance. Furthermore, compared to tuberculosis skin tests, the introduction of interferon- $\gamma$ assays has largely improved the specificity of LTBI detection; thus, the number of patients that would receive preventive treatment without needing it can be reduced. This knowledge might raise the motivation of healthcare workers in their efforts to follow patients and help them adhere to the proposed treatment.

Our study has several weaknesses. The small size of the population sample led to a lack of precision in the results. The absence of a non-migrant control group made it difficult to compare the prevalence of LTBI in migrants with that of the local population; however, we considered it safe to assume that the local population living in Switzerland had a much lower prevalence of LTBI than the study population. The setting of our study could limit the generalisability of our results to rural migrants attending a healthcare centre. Patients who do not attend a healthcare centre could be younger and less deprived than those included in the study. Our population could be more at risk to have been in contact with tuberculosis. Our results are therefore limited to quantifying the prevalence of 


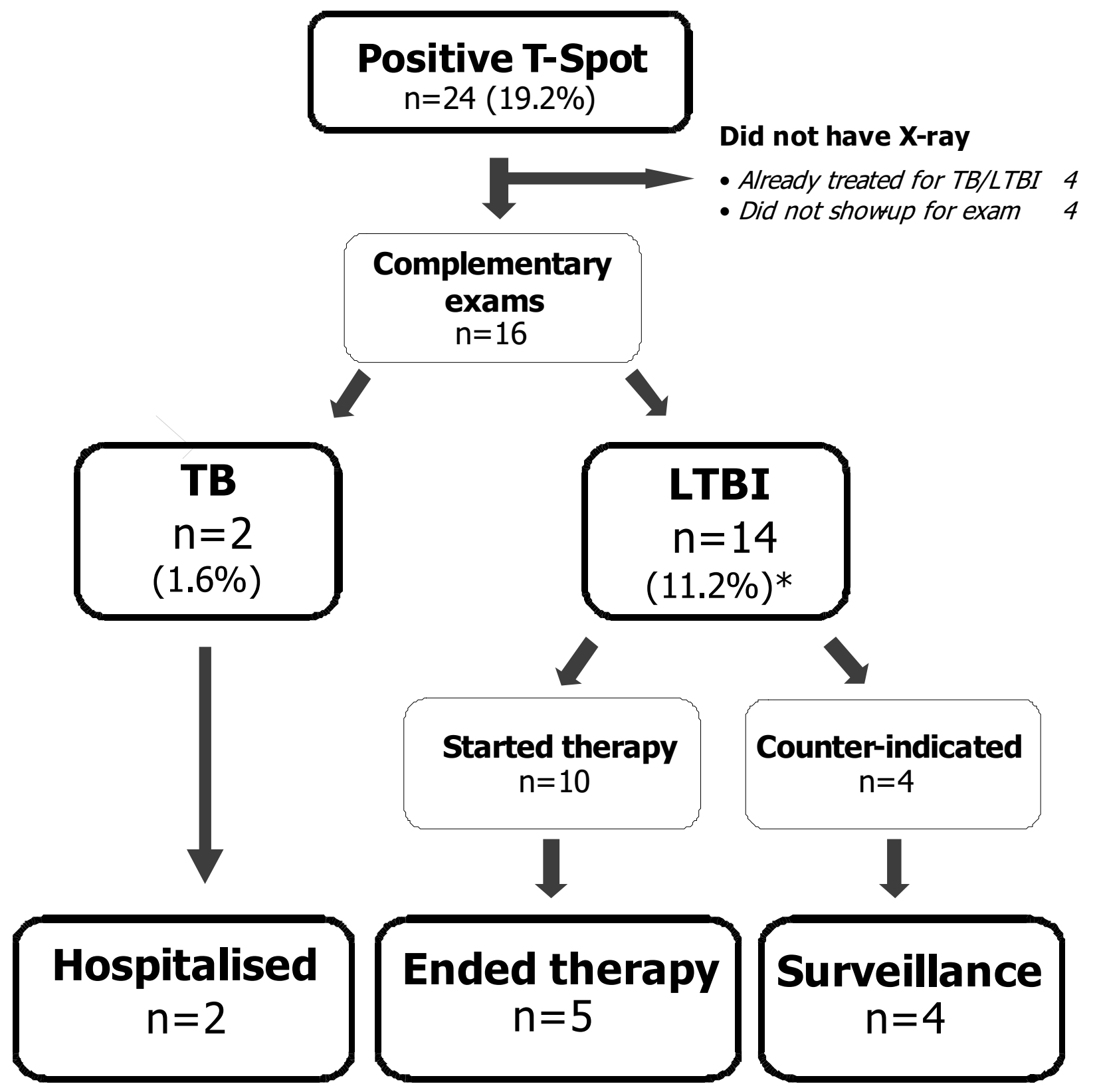

Figure 2

Adherence to therapy from testing to the end of prophylactic therapies. * Total number of participants with LTBI was expected to be 18 . We assumed that the four patients that did not show up for further examination did not have active TB.

latent tuberculosis in a setting in which it is possible to consider targeted screening and prevention programs to take place. Finally, interferon- $\gamma$ positivity may not equate perfectly with latent $\mathrm{TB}$ infection. As such additionally data using another interferon- $\gamma$ or the tuberculosis skin test would have been helpful.

\section{Conclusion}

Our study shows the benefit of using highly sensitive assays for detecting LTBI on targeted populations at risk that easily accept screening in appropriate health settings by trained nurse practitioners and primary care physicians. Nevertheless, methods for improving adherence to 
treatment are lacking. Our results demonstrate the high prevalence of LTBI in migrants and emphasize the need for developed countries to invest in programs that reduce the transmission of tuberculosis worldwide; in particular, the focus should be on undocumented migrants that frequently come from countries with high incidence rates of tuberculosis.

\section{Abbreviations}

LTBI: latent tuberculosis infection; TB: active tuberculosis; CI: confidence interval; HIV: human immunodeficiency virus.

\section{Competing interests}

The authors declare that they have no competing interests.

\section{Authors' contributions}

PB has made substantive contribution to conception, acquisition of data, design and interpretation of data. PV has contributed to conception, design, analysis and interpretation of data. PB and PV have drafted the manuscript. $\mathrm{HW}, \mathrm{BF}$ and EM have contributed to the interpretation of data and critically revised the manuscript. FdT has contributed to acquisition of data and revising the manuscript. JPZ has made contribution to conception and design, interpretation of data and has revised the manuscript with important intellectual content. All authors have given their approval for this version to be published.

\section{Acknowledgements}

We thank those who have financed our study: The State Department of Health of Vaud, the Migration Friendly Hospital Association, and the Swiss Lung League.

\section{References}

I. Dye C, Scheele S, Dolin P, Pathania V, Raviglione MC: Consensus statement. Global burden of tuberculosis: estimated incidence, prevalence, and mortality by country. WHO Global Surveillance and Monitoring Project. Jama 1999, 282(7):677-686.

2. WHO: Global tuberculosis control: surveillance, planning, financing. WHO report 2007. 2007 [http://www.who.int/tb/pub lications/global report/2007/pdf/full.pdf]. Geneva: WHO

3. MacPherson DW, Gushulak BD: Balancing prevention and screening among international migrants with tuberculosis: population mobility as the major epidemiological influence in low-incidence nations. Public health 2006, I 20(8):7| 2-723.

4. Walls $T$, Shingadia D: The epidemiology of tuberculosis in Europe. Archives of disease in childhood 2007, 92(8):726-729.

5. Laifer G, Widmer AF, Simcock M, Bassetti S, Trampuz A, Frei R, Tamm M, Battegay M, Fluckiger U: TB in a low-incidence country: differences between new immigrants, foreign-born residents and native residents. The American journal of medicine 2007, I 20(4):350-356.

6. Dahle UR, Eldholm V, Winje BA, Mannsaker T, Heldal E: Impact of immigration on the molecular epidemiology of Mycobacterium tuberculosis in a low-incidence country. American journal of respiratory and critical care medicine 2007, I76(9):930-935.

7. Lillebaek T, Andersen AB, Bauer J, Dirksen A, Glismann S, de Haas P, Kok-Jensen A: Risk of Mycobacterium tuberculosis transmission in a low-incidence country due to immigration from high-incidence areas. Journal of clinical microbiology 200I, 39(3):855-86।.
8. Dahle UR, Sandven P, Heldal E, Caugant DA: Continued low rates of transmission of Mycobacterium tuberculosis in Norway. Journal of clinical microbiology 2003, 4 I (7):2968-2973.

9. Maguire H, Dale JW, McHugh TD, Butcher PD, Gillespie SH, Costetsos A, Al-Ghusein H, Holland R, Dickens A, Marston L, et al.: Molecular epidemiology of tuberculosis in London 1995-7 showing low rate of active transmission. Thorax 2002, 57(7):617-622.

10. Welshman J, Bashford A: Tuberculosis, migration, and medical examination: lessons from history. Journal of epidemiology and community health 2006, 60(4):282-284.

II. Rieder HL, Zellweger JP, Raviglione MC, Keizer ST, Migliori GB: Tuberculosis control in Europe and international migration. Eur Respir J 1994, 7(8): 1545-1553.

12. Lalvani A: Spotting latent infection: the path to better tuberculosis control. Thorax 2003, 58(II):916-918.

13. Blumberg HM, Leonard MK Jr, Jasmer RM: Update on the treatment of tuberculosis and latent tuberculosis infection. Jama 2005, 293(22):2776-2784.

14. Chee CB, Teleman MD, Boudville IC, Do SE, Wang YT: Treatment of latent TB infection for close contacts as a complementary TB control strategy in Singapore. Int J Tuberc Lung Dis 2004, 8(2):226-23I.

15. Menzies D, Pai M, Comstock G: Meta-analysis: new tests for the diagnosis of latent tuberculosis infection: areas of uncertainty and recommendations for research. Annals of internal medicine 2007, I 46(5):340-354.

16. Ewer K, Deeks J, Alvarez L, Bryant G, Waller S, Andersen P, Monk P, Lalvani A: Comparison of T-cell-based assay with tuberculin skin test for diagnosis of Mycobacterium tuberculosis infection in a school tuberculosis outbreak. Lancet 2003, 36I(9364): II68-1173.

17. Dasgupta K, Menzies D: Cost-effectiveness of tuberculosis control strategies among immigrants and refugees. Eur Respir J 2005, 25(6): $1107-1116$.

18. Porco TC, Lewis B, Marseille E, Grinsdale J, Flood JM, Royce SE: Cost-effectiveness of tuberculosis evaluation and treatment of newly-arrived immigrants. BMC public health 2006, 6:157.

19. Oxlade O, Schwartzman K, Menzies D: Interferon-gamma release assays and TB screening in high-income countries: a cost-effectiveness analysis. Int J Tuberc Lung Dis 2007, II (I): I6-26.

20. Diel R, Nienhaus A, Loddenkemper R: Cost-effectiveness of interferon-gamma release assay screening for latent tuberculosis infection treatment in Germany. Chest 2007, |3 |(5): | 424-| 434.

21. Coker R: Compulsory screening of immigrants for tuberculosis and HIV. BMJ (Clinical research ed) 2004, 328(7435):298-300.

22. Zellweger JP, Helbling P: Tuberculosis in Switzerland: from sanatorium guests to immigrants. Monaldi Arch Chest Dis 1997, 52(3):234-236.

23. Bodenmann P, Depallens VM, Schoch M, Puelma M, Pécoud A, Gehri M: Etre malade et "sans-papiers" à Lausanne: Quo vadis? Médecine et Hygiène 2003, 545:2023-2028.

24. Longschamps C, Aebersold E, Rousselot B, Ratelband-Pally S: "Sanspapiers" in der Schweiz Arbeitsmarkt, nicht Asylpolitik istentscheidend. 2005.

25. Carvalho AC, Pezzoli MC, El-Hamad I, Arce P, Bigoni S, Scarcella C, Indelicato AM, Scolari C, Carosi G, Matteelli A: QuantiFERON-TB Gold test in the identification of latent tuberculosis infection in immigrants. The Journal of infection 2007, 55(2): $164-168$.

26. Pai M, Zwerling A, Menzies D: T-Cell-Based Assays for the Diagnosis of Latent Tuberculosis Infection: An Update. Ann Intern Med 2008, I49(3): I77-184.

27. Ligue Pulmonaire Suisse: Manuel de la Tuberculose. 2007 [http:/ /www.tbinfo.ch/uploads/media/

Handbuch Tuberkulose f 140507.pdf].

28. Zelwegger J-P: Treatment of tuberculosis. Expert Rev Respir Med 2007, I I I : :85-97.

29. Diel R, Nienhaus A, Lange C, Schaberg T: Cost-optimisation of screening for latent tuberculosis in close contacts. Eur Respir J 2006, 28(I):35-44.

30. Soborg B, Andersen AB, Larsen HK, Weldingh K, Andersen P, Kofoed $K$, Ravn P: Detecting a low prevalence of latent tuberculosis among health care workers in Denmark detected by $M$. tuberculosis specific IFN-gamma whole-blood test. Scandinavian journal of infectious diseases 2007, 39(6-7):554-559. 
31. Harada N, Nakajima Y, Higuchi K, Sekiya Y, Rothel J, Mori T: Screening for tuberculosis infection using whole-blood interferongamma and Mantoux testing among Japanese healthcare workers. Infect Control Hosp Epidemiol 2006, 27(5):442-448.

32. Mazurek GH, Zajdowicz MJ, Hankinson AL, Costigan DJ, Toney SR, Rothel JS, Daniels LJ, Pascual FB, Shang N, Keep LW, et al.: Detection of Mycobacterium tuberculosis infection in United States Navy recruits using the tuberculin skin test or whole-blood interferon-gamma release assays. Clin Infect Dis 2007 , 45(7):826-836.

33. Mori T, Harada N, Higuchi K, Sekiya Y, Uchimura K, Shimao T: Waning of the specific interferon-gamma response after years of tuberculosis infection. Int J Tuberc Lung Dis 2007, I I (9): I02I-I025.

34. Patel S, Parsyan AE, Gunn J, Barry MA, Reed C, Sharnprapai S, Horsburgh CR Jr: Risk of progression to active tuberculosis among foreign-born persons with latent tuberculosis. Chest 2007, 131(6): $|8||-| 8 \mid 6$.

35. Smieja MJ, Marchetti CA, Cook DJ, Smaill FM: Isoniazid for preventing tuberculosis in non-HIV infected persons. Cochrane database of systematic reviews (Online) 2000:CD00I 363.

36. Diel R, Wrighton-Smith P, Zellweger JP: Cost-effectiveness of interferon-\{gamma\} release assay testing for the treatment of latent tuberculosis. Eur Respir J 2007, 30(2):32I-332.

37. Wrighton-Smith $P$, Zellweger JP: Direct costs of three models for the screening of latent tuberculosis infection. Eur Respir J 2006, 28(I):45-50.

38. Reynard C, Zuberbuehler D, Zellweger J: Tuberculosis among illegal immigrants in Lausanne, Switzerland. Conférence mondiale sur la tuberculose et les maladies respiratoires. Paris. 200I.

39. Diel R, Loddenkemper R, Meywald-Walter K, Niemann S, Nienhaus A: Predictive Value of a Whole-blood IFN-\{gamm\} Assay for the Development of Active TB Disease. American journal of respiratory and critical care medicine 2008, I77(10): I 164-70.

40. Bayoumi AM, Hwang SW: Methodological, practical, and ethical challenges to inner-city health research. J Urban Health 2002, 79(4 Suppl I):S35-42.

41. Ailinger RL, Moore JB, Nguyen N, Lasus H: Adherence to latent tuberculosis infection therapy among latino immigrants. Public health nursing (Boston, Mass) 2006, 23(4):307-313.

42. Racine-Perreaud E, Zellweger JP: Chimiothérapie antituberculeuse préventive chez 250 patients du Dispensaire antituberculeux de Lausanne. Schweizerische medizinische Wochenschrift I994, I 24(I 7):705-7|I.

43. Matteelli A, Casalini C, Raviglione MC, El-Hamad I, Scolari C, Bombana E, Bugiani M, Caputo M, Scarcella C, Carosi G: Supervised preventive therapy for latent tuberculosis infection in illegal immigrants in Italy. Am J Respir Crit Care Med 2000, I 62(5): 1653-1655.

44. Moulding TS: Viewpoint: adapting to new international tuberculosis treatment standards with medication monitors and DOT given selectively. Trop Med Int Health 2007, I 2(I I): I302-1308.

45. Marjanovic Z, Tuppin P, Herrmann JL, Bayol G, Toledano C, Farge D: Tuberculosis in patients with and without primary health coverage. Eur J Intern Med 2002, I3(3): $180-184$.

46. McEwen MM: Mexican immigrants' explanatory model of latent tuberculosis infection. J Transcult Nurs 2005, 16(4):347-355.

47. Horrocks S, Anderson E, Salisbury C: Systematic review of whether nurse practitioners working in primary care can provide equivalent care to doctors. BMJ (Clinical research ed) 2002, 324(734I):819-823.

48. Koehn PH, Sainola-Rodriguez K: Clinician/patient connections in ethnoculturally nonconcordant encounters with politicalasylum seekers: a comparison of physicians and nurses. I Transcult Nurs 2005, 16(4):298-3II.

\section{Pre-publication history}

The pre-publication history for this paper can be accessed here:

http://www.biomedcentral.com/1471-2334/9/34/prepub
Publish with Biomed Central and every scientist can read your work free of charge

"BioMed Central will be the most significant development for disseminating the results of biomedical research in our lifetime. "

Sir Paul Nurse, Cancer Research UK

Your research papers will be:

- available free of charge to the entire biomedical community

- peer reviewed and published immediately upon acceptance

- cited in PubMed and archived on PubMed Central

- yours - you keep the copyright
BioMedcentral 